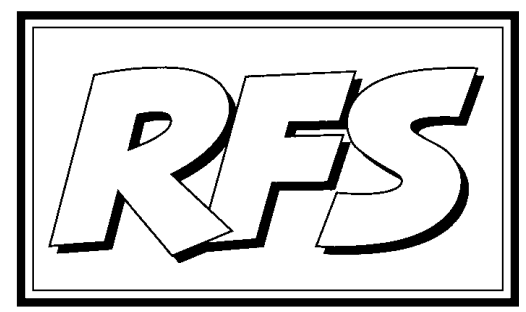

Revista de Fomento Social, 56 (2001), 679-694

\title{
La población inmigrante de origen extranjero y su impacto en las sociedades europeas
}

Lluís RECOLONS ARQUER, SJ

\section{Introducción}

Al pretender introducir el tema de la inmigración y sus consecuencias en la Europa de hoy se topa uno a cada paso con la cuestión de la complejidad que ofrece. Así sucede al tratar, tanto los datos cuantitativos, como las situaciones y los procesos cualitativamente considerados; y todavía más al entrar en el terreno de las interpretaciones de las migraciones y de lo que ellas comportan en nuestro mundo. Por todo ello, valga decir al inicio de este escrito que cualquier intento de ofrecer una visión englobante de la compleja totalidad del tema queda mucho más allá de su objetivo. Esta breve exposición no pretende más que presentar algunas características significativas

1 Migra-Studium, Barcelona. Ponencia presentada en la reunión del grupo EUROJ ESS 2001. Véase crónica de dicha reunión en este mismo número. 
que enmarcan la actualidad del tema en Europa, y de alguna manera, en el mundo.

Los procesos migratorios pasan por diversas fases a lo largo del tiempo, no sólo durante la vida de los individuos que realizaron la migración, sino de la de algunos de sus descendientes. Resulta totalmente inadecuado llamar inmigrantes a los hijos y nietos nacidos ya en el país al que emigraron sus padres o sus abuelos, e incluso para estos progenitores que, efectivamente, un día llegaron desde otro país, pues aunque esta condición ofrezca alguna base para considerar los inmigrados, no obstante, en la mayoría de los casos con el correr de los años en el país de destino, esta denominación suele ir quedando desvalorizada, sociológicamente, cuanto menos, como calificativo preponderante de la ubicación de estas personas en la sociedad, al ir confluyendo y superponiéndose en ellas otras cualificaciones de status, tanto o más significativas del lugar que están ocupando en la sociedad. En cambio, la sociología y la psicología coinciden en extender las fases de los procesos migratorios más allá de los ciclos vitales individuales. La última fase de este proceso podría considerarse que concluiría con "la reconstitución de la familia de tres generaciones"2 en el lugar de destino.

La diferencia en la percepción del "bien-estar" neto percibido entre los lugares de origen y los lugares de destino es la que acaba decidiendo la migración, cuando tales diferencias llegan a alcanzar un umbral que resulta determinante para el individuo. Estas decisiones con frecuencia ni las toma sólo el individuo que efectivamente emigra ni le afectan únicamente a él, sino que forman parte de estrategias familiares y grupales. Con mayor adelanto o retraso, los diferentes países de la Unión Europea de histórica tradición emigratoria han pasado a ser países de inmigración de poblaciones procedentes de otros continentes y de la misma Europa.

\section{Prevalencia de fases avanzadas en los procesos migratorios en curso}

1. La misma complejidad mencionada inicialmente es ya una primera característica significativa de las migraciones actuales y sus consecuencias. La progresiva concienciación de esta complejidad está en la base de la constatación generalizada en los últimos años entre los estudiosos de las migraciones, especialmente de las migraciones internacionales, de la caren-

2 Así lo considera PISElLi (1997), p. 9, siguiendo a WeBNER (1990). 
cia de una teoría general de las migraciones, capaz de abarcar las múltiples facetas que presentan actualmente estos temas. Ello no implica una descalificación general de los desarrollos teóricos realizados ${ }^{3}$, útiles, e incluso necesarios, algunos de ellos. La contrapartida de no tener suficientemente en cuenta la complejidad del fenómeno es la frecuente simplificación en el tratamiento de las temáticas relacionadas con las migraciones. De ahí se derivan, por ejemplo, los excesos en la atribución de homogeneidades individuales o colectivas entre las poblaciones originadas por la inmigración, precisamente cuando los países que reciben más inmigrantes se encuentran hoy en un proceso de creciente diversidad de origen de la población. Asimismo a los europeos (y no sólo a ellos) les llegan con demasiada frecuencia imá genes unilatera les y proclives al estereotipo, de la población originada por la inmigración de extranjeros. Unas imágenes construidas a veces, no tanto de acuerdo con su valor significativo para dar a conocer la realidad compleja del fenómeno, sino según el color del cristal de quienes las difunden buscando titulares llamativos.

2. En la actualidad, la atención pública a las cuestiones relacionadas con el control de entradas de nuevos inmigrantes internacionales y con las fases iniciales de los procesos migratorios no ha de hacer olvidar que en Europa la mayoría de las población originada por las migraciones se encuentra en fases avanzadas de sus procesos migratorios. Incluso algunas de las características de los nuevos inmigrantes extranjeros a los países europeos resultan indicadores de inmigrantes llegados con anterioridad ${ }^{4}$.

3. El establecimiento en los países europeos de quienes un día llegaron como inmigrantes extranjeros es una realidad que ha ido encontrando dificultades y retrasos considerables para ser admitida como tal, debido a actitudes encastilladas, a veces, en supuestos legales inadecuados para expresar la realidad social realmente operativa. Tal ha sido el caso de prolongar a la población originada por la inmigración de extranjeros la

3 La falta de una teoría general aceptada coexiste con la existencia de teorías que pueden resultar útiles si se las utiliza de acuerdo con las posibilidades reales que ofrecen. Unas posibilidades que, en algunos casos, podrían llegar a considerarlas como teorías de rango intermedio, capaces de ofrecer el marco adecuado para ubicar un conjunto de sectores sociales, pero no la generalidad de los que se relacionan con las migraciones y sus consecuencias. (Cfr. Recolons, L. (2001), p. 39).

4 Así, por ejemplo, entre los nuevos inmigrantes a los países desarrollados, la prioridad cuantitativa se la están llevando, según los datos más recientes, los inmigrantes llegados en razón de sus vínculos familiares (OECD/SOPEMI 2000). 
consideración de "trabajadores extranjeros huéspedes" (Gastabeiter) , generalizada en los años 1950. Estos retrasos y reluctancias no son equivalentes en los diversos países europeos receptores de migrantes extranjeros, pero están bastante generalizados en el conjunto de Europa ${ }^{5}$. No obstante, en la proliferación de declaraciones oficiales y disposiciones administrativas en diversos países europeos en los últimos años y meses se observan avances considerables en la admisión de que la situación real, y todavía más, la perspectiva previsible de futuro es la de la permanencia estable de una abundante población de origen extranjero en muchos países europeos. Con ello, un estado de cosas que ha estado operando, de hecho, desde algunos decenios, actuando como lastre para la aplicación más efectiva de políticas y prácticas ciudadanas de integración puede haber dado algunos pasos significativos en la vía de un tratamiento más adecuado a las exigencias de la realidad. Aunque todavía las realizaciones consecuentes con tal admisión oficial de la realidad se encuentren a veces alejadas de la misma, y no impliquen, por sí mismas, que diversos sectores de la población y de las mismas administraciones públicas orienten sus actitudes en el sentido integrador indicado.

4. De todo ello resulta que, dentro de la mutua interacción y complementariedad entre las políticas de control de flujos y las políticas de integración, necesarias ambas en Europa, ahora es el tiempo de dar prioridad a las políticas de integración. Ha sido una característica excesivamente frecuente en los diversos estados europeos, no sólo el hecho de que el peso de las políticas relacionadas con la población inmigrante empezaran cronológicamente por las medidas de control y represión, sino también la frecuente subordinación del conjunto de políticas relacionadas con la inmigración y sus consecuencias a una lógica policial excesivamente preponderante ${ }^{6}$. Tal práctica ha producido disfunciones considerables en relación a la integra-

5 En este sentido recapitulaba ya en 1990 el sociólogo holandés Han B. Entzinger las políticas de los países europeos a los cuales llegaron con mayor antelación los inmigrantes extranjeros, tras la segunda guerra mundial. Durante gli anni Settanta e Ottanta, la magior parte dei paese de l'Europa Occidentale iniziò a ricognoscere che, contrariamente a quanto si credeva prima, molti dei loro immigrati sarebbero rimasti. (ENTZINGER (1990), p. 185).

6 No se trata de negar el reconocimiento del papel que en el conjunto de políticas relacionadas con la migración y sus consecuencias, las políticas de control y la función represiva del estado, en sus diversos niveles, tengan también una función a cumplir. Las políticas de control tienen también su ámbito de exigencias. La crítica va a la excesiva preponderancia concedida a dichas políticas de control en determinar la globalidad de las respuestas, desde las administraciones públicas de los países receptores. 
ción de los inmigrantes 7 : favoreciendo el que las dificultades normalmente abundantes en los inicios de los procesos migratorios, debidas a desajustes sociales y culturales, en vez de seguir el proceso normal de superación, pasasen, en más casos de los previsibles, a cronificarse en situaciones tendentes a la exclusión social. Pero es que, además, aquella preponderancia ha favorecido también la proliferación de inmigrantes en situación irregular, que era lo que se pretendía evitar, precisamente con la excesiva rigidez de las mismas políticas de control. En efecto, entre las causas de la abundancia de inmigrantes en situación irregular, no sólo hay que contar las que provienen de la presión por entrar, sino también a las derivadas de las excesivas trabas a la concesión de un status legal en respuesta a las solicitudes iniciales, o de las dificultades a la renovación del mismo. Estas dificultades dejan a una abundante población de origen extranjero en situación de irregularidad o precariedad legal. Para muchos resulta prácticamente imposible encontrar vías normalizadas para regularizar su situación irregular. Ello, a su vez constituye un poderoso estimulante para que se desarrollen las mafias y las corrupciones administrativas e incluso ha llegado a ser, en al gunos casos no infrecuentes, factor estimulante de la misma delincuencia que se pretendía evitar ${ }^{8}$.

\section{De la integración de los inmigrantes a la integración de la sociedad}

\section{El término integración en relación a los inmigrantes internacionales} y sus descendientes se ha hecho hoy omnipresente en el lenguaje político y mediático. Y a la vez es objeto de frecuentes y encontrados debates en el ámbito académico. El obstáculo principal para su aceptación es el peligro real o posible de tratar de encubrir bajo otro nombre lo que no sería más que un intento de pura asimilación. Es decir, de pretender la desaparición de to do rasgo sociocultural específico de la población de origen inmigrante, al

7 Así, por ejemplo, la misma inseguridad respecto a las posibilidades de permanencia en el país, además de dificultar la inserción laboral, aumentar las posibilidades de abuso y la ansiedad vital, desmotiva, lógicamente, el aprendizaje de la lengua y de las formas de vida de la sociedad de destino, ante la incertidumbre de si tal permanencia pueda encontrarse repentinamente truncada.

8 No son raros los casos de inmigrantes extranjeros encarcelados que han buscado tal situación, cometiendo pequeños delitos, como medio de asegurarse un periodo de permanencia en el país de destino, frente a la inseguridad de una situación expuesta constantemente a la detención y expulsión del país. 
quedar engullido en la población de la sociedad receptora. En la práctica, no obstante, son muchos los estudiosos del tema que no pueden zafarse de la utilización generalizada del término, aunque indiquen reluctancias al mismo. Otros lo evitan absolutamente, y otros lo utilizan sujetándose a la metodología ortodoxa de explicitar la definición ${ }^{9}$ que atribuyen al término y tratan de adecuarse a la misma en el discurrir subsiguiente.

6. De la integración de los inmigrantes a la integración de la sociedad. En 1990 Stany Grudzielski ${ }^{10}$ hacía notar que originariamente en ciencias sociales el término integración se entendía como un atributo de la sociedad y no se utilizaba en el sentido, más generalizado ahora al aplicarlo a los inmigrantes, un atributo de los individuos. Esta observación, ya sugerente al comenzar el anterior decenio, ha visto aumentar su interés en los últimos años, cuando ponderados análisis y diagnósticos de la realidad social han venido advirtiendo que una parte, no pequeña, de la población, dentro de los mismos estados europeos va quedando distanciada, marginada o excluida de la participación en el bienestar conseguido. La población inmigrante y su descendencia se verá en parte afectada por esta situación, y más adelante nos referiremos a ello. Pero con independencia y anterioridad al impacto que origine y que reciba esta población de origen foráneo en la integración de la sociedad, hay que reconocer en el funcionamiento de los sistemas sociales de nuestras sociedades, que junto a factores que juegan a favor de la integración y cohesión social, juegan también fuerte otros factores desintegradores. Las situaciones de pobreza, marginación y exclusión de unas importantes minorías de las poblaciones de raíces autóctonas dejan ver que la reducción de la temática de la integración a la población de origen extranjero no resulta adecuada. Recientemente la Comisión Europea se hacía eco de estas situaciones entre las poblaciones de los países miembros.

9 Así por ejemplo Antonio Perotti (1993), p. 69: “L'intégration est le processus graduel par lequel les nouveaux résidents deviennent des participants actives à la vie économique, sociale, civique, culturelle et spirituelle du pays d'immigration". Y añadirá: "Afin de lever certaines ambigüitées qui pourraient résulter de l'usage courant du mot intégration -incorporation d'une partie dans un tout- nous pourrions choisir, comme le suggère Claude Clanet, l'expression intégration plurielle".

10 La lúcida exposición de Stany Grudzielski en N.D de Laus (Departament de Gap) en los preAlpes franceses (agosto 1990), analizaba críticamente los trasfondos ideológicos del uso político de algunos de los términos más utilizados (integración, identidad...) al tratar de las migraciones internacionales (Cfr. GRUDZIELSKI (1990)). Sobre el uso de los conceptos: asimilación, aculturación, integración, especialmente en los autores franceses más significados en los últimos años (Cfr. M. BOucher (2000)). 


\section{Inmigrantes y marginación: equivalencias inadecuadas}

\section{Inadecuación de la tendencia a ubicar principalmente el tratamiento} de la población de origen inmigrante extranjero en el ámbito temático de la marginación: 0 migrante e, ante tudo, un forte. Esta rotunda frase atribuida al célebre escritor brasileño Euclides da Cunha condensa lo que es una reiterada constatación de las investigaciones sobre lo que han sido y son los inmigrantes. La migración y, en concreto, la migración internacional a Europa selecciona positivamente. No son los más pobres ${ }^{11}$ entre los africanos, ni entre los asiáticos, ni entre los europeos del este o del continente americano los que emigran a Europa. Los más pobres no tienen los recursos requeridos para ejecutar una decisión de este calibre. Pero no se trata simplemente de una selección por factores económicos. La selección positiva afecta a la prevalencia entre la población migrante de condiciones de fortaleza concomitantes a la edad y a condiciones anímicas de empuje y aguante para soportar la dureza de las dificultades inherentes al hecho de migrar. No se trata de mitificar idealmente a las poblaciones migrantes, entre las cuales, naturalmente, dado que comprenden frecuentemente colectivos numerosos, habrá que contar la inclusión también de individuos que no participan de estas condiciones atribuibles a la gran mayoría de los que llegan a Europa. Pero sería (y ha sido con demasiada frecuencia) una orientación equivocada considerar al inmigrante como un incapacitado social, encuadrándole excesivamente en el círculo de políticas para marginados.

8. Realidad e imagen de las situaciones de marginación entre la población de origen inmigrante. La afirmación del párrafo anterior coexiste con reales situaciones de marginación y exclusión entre la población originada por la inmigración de extranjeros en Europa. La más arraigada y difícil de superar es aquella en la cual la larga convivencia en contextos de margina-

11 Ello no quita que en el mundo abunden también las migraciones para sobrevivir, tales como por ejemplo las provocadas por hambrunas, catástrofes naturales guerras y persecuciones étnicas, políticas, religiosas, etc. A nivel mundial, la mayoría de los desplazamientos originados por estas causas se dan en países africanos, asiáticos, latinoamericanos y se trata mayoritariamente de desplazamientos internos dentro del país, o a los países vecinos. En el último decenio, en Europa se han producido situaciones de este tipo, siendo las más relevantes las originadas por las sucesivas crisis de la ex Yugoslavia. Además, han solicitado asilo en países europeos refugiados de procedencia muy variada con respuestas diferentes según los países solicitados, pero dentro de una tendencia europea, tendente generalmente, a la restricción de concesiones de status de asilado. 
ción hubiera llegado a afectar la capacidad de superación de los individuos, resultando crónica, y en este sentido su exclusión social andaría pareja con las dificultades de los marginados crónicos autóctonos. No obstante, entre el conjunto de las poblaciones autóctonas europeas son frecuentes las imágenes de poblaciones originadas de las inmigraciones de extranjeros ${ }^{12}$ que desorbitan la magnitud de la implantación de este tipo cronificado de exclusión social de difícil recuperación. Facilita esta confusión la percepción de abundantes situaciones reales de pobreza y de deficiencias sociales y diferencias culturales que tipifican las fases iniciales, e incluso las ya avanzadas, de los procesos migratorios. La movilidad social de los hijos y nietos de los inmigrantes respecto a sus antecesores resulta un indicador clave en la percepción del éxito de los proyectos migratorios. La dureza que suele conllevar la migración se da por bien empleada si los hijos pueden gozar de un status digno y superior al que ocuparon sus padres en la sociedad a la que emigraron. Si por el contrario, estos descendientes de quienes inmigraron encuentran cerrado el camino de movilidad social, por el hecho de su estirpe extranjera, el proceso migratorio puede llegar a producir un profundo sentimiento de frustración y la cohesión social puede resultar resquebrajada en una sociedad en la que abunden tales situaciones. De ahí la importancia de prevenirlas y de facilitar la potente dinámica desuperación de dificultades que caracteriza muy mayoritariamente a la población inmigrada.

\section{Integración y exclusión en las sociedades europeas}

9. Las poblaciones europeas tras la incorporación de la población de origen foráneo. La brevedad de este escrito no permite un recorrido país por país. El panorama que ofrece cada uno de ellos al respecto es diverso, dependiendo de muchos factores; entre ellos: el tiempo transcurrido desde el inicio de estas migraciones, la magnitud de los flujos, los orígenes concretos y más o menos diversificados de los inmigrantes extranjeros, las actitudes de las poblaciones autóctonas y las políticas efectivas de los gobiernos

12 La población nacida ya en el país de destino, descendiente de inmigrantes extranjeros es por naturaleza población autóctona, más allá de lo que puedan tipificar las mudables legislaciones en los diversos países. En sucesivas generaciones el fenotipo de los individuos puede ir reproduciendo características físicas diferenciales respecto a las de los descendientes de población blanca europea. La incongruencia con los datos de la ciencia y con los derechos humanos proclamados sería total, si tales características supusieran discriminaciones sociales significativas. 
a lo largo de los procesos migratorios, etc. No obstante la existencia real de conflictos y tensiones que demasiadas veces desembocan en discriminaciones y agresiones de efectos negativos para la integración de la sociedad, es importante no perder de vista los procesos que con menos ruido avanzan en los caminos de incorporación de poblaciones de origen extranjero a las sociedades europeas. Con diferencias en los diversos países europeos, es perceptible su presencia en más sectores sociales, y su ascenso (más o menos lento o rápido) por los escalones de status social.

10. Áreas sociales específicas y guettos cerrados. Dentro de la multiplicidad de posibles desarrollos de los procesos migratorios alarma, con frecuencia, la posibilidad de que lleguen a producirse guettos aislados e impermeables que dificulten la cohesión del conjunto dela sociedad. Es una posibilidad real y peligrosa. No hay que confundirla, no obstante, con la existencia de ámbitos específicos de interrelación entre población de los mismos orígenes, que pueden realizar funciones de integración social, precisamente al facilitar la preservación y la evolución en las identidades individuales y grupales, evitando situaciones de anomía y de desestructuración de las personalidades. Muchos procesos migratorios históricamente concluidos con éxito han pasado por largos períodos de intensa vida social de estos ámbitos sociales específicos.

11. Escenarios prospectivos. Desde un punto de vista cuantitativo, las Naciones Unidas ${ }^{13}$ y la Unión Europea ${ }^{14}$ han presentado escenarios prospectivos de la población en los cuales resaltan incrementos sustanciales de la participación en la población total de las poblaciones que han tenido su origen en las inmigraciones de extranjeros. En lo que respecta al futuro de la integración de la sociedad en los diversos países europeos receptores de inmigración extranjera, nos limitamos aquí15 a señalar muy esquemática-

13 Naciones Unidas (2000) Replacement Migrations: Is it a Solution to Declining and Ageing Populations?, Population Division.

${ }^{14}$ Comisión Europea (2000) Comunicación de la Comisión al Consejo y al Parlamento Europeo sobre una política comunitaria de inmigración, Bruselas, 22 de noviembre.

15 Me he ocupado del tema de los escenarios cualitativos de la inmigración, en relación a la población norteafricana en Cataluña, para el período 1990-2000, en: RECoLons, L. (1989) "Esbós de prospectives per a la població d'origen nord-africà a Catalunya en el període 19902000", (pp. 295-316) en Els Moviments Humans en el Mediterrani Occidental, Simposium Internacional, Roque, Ma Angels (ed.), Institut Català d'Estudis Mediterranis, Barcelona. Traducción castellana de la tercera parte del artículo: "Dos escenarios para la inmigración norteafricana en Cataluña en el año 2000" en Pastoral Misionera, № 180, El Islam, Editorial 
mente cuatro escenarios tipo: dos escenarios polares en los extremos y otros dos intermedios:

Los escenarios polares por su misma tipificación extremada son menos plausibles que los escenarios intermedios, pero su caracterización puede resultar teóricamente clarificadora.

Escenario polar de separación: una sociedad con una amplia área central, en la cual la participación en los diversos sectores de la vida social está acaparada por la mayoría de la población autóctona, y donde poblaciones de algunos orígenes extranjeros encuentran muy limitadas posibilidades de ocupar un lugar. Coexistiendo con el área central, unas áreas periféricas específicas ofrecen el terreno donde diversas poblaciones minoritarias ocupan principalmente su vida social, con tendencia al aislamiento respecto al área central.

Escenario polar de asimilación: un área, prácticamente única, en la cual han desaparecido casi todos los rasgos específicos de la poblaciones de diversos orígenes, al ser asimilad os por la población autóctona. Las huellas de los orígenes de las diversas poblaciones que inmigraron anteriormente al país, perceptibles en la conducta y en la participación social, han quedado reducidas a algunos rasgos dispersos considerados pintorescos o folclóricos.

Los escenarios intermedios, dentro también del forzado esquematismo con el que aquí se describen, tienen más probabilidades de realización que los escenarios polares. Aunque las modalidades y combinaciones concretas que pueda ofrecer la realidad son innumerables, los dos escenarios intermedios que se indican a continuación tendrían en común la existencia de una área central y unas áreas periféricas específicas, y a la vez la intercomunicación entre ellas.

Escenario intermedio de más juego en las áreas específicas: dentro de una participación e intercomunicación abundantes entre el área central y las periféricas que caracterizan a ambos escenarios intermedios, el primero

Popular, Madrid 1992, pp.66-85. Y en referencia al conjunto de la población africana, también en Cataluña, para el período 1997-2006, en el estudio inédito de ReCoLons, L. (1997) “Los procesos migratorios de origen africano en Cataluña de 1997 a 2006" (pp. 71-132) en Domingo, A.; OSÁCAR, R.; RECOLONS, L. (1997), Integración de la población inmigrada de origen africano y de su descendencia en Cataluña. Escenarios prospectivos para el horizonte 2006, Centre d'Estudis Demogràfics (UAB) subvencionado por la Dirección General de Trabajo y Migraciones del Ministerio de Trabajo y Asuntos Sociales. 
mantiene todavía ciertas dificultades al acceso a algunos sectores del área social central para determinadas poblaciones de origen extranjero. Correlativamente, la población total tiende a una menor incorporación de elementos culturales propios de las áreas específicas. Estas áreas específicas, a su vez, están menos abiertas al conjunto de la población total que en el escenario siguiente.

Escenario intermedio de más juego en el área central. En este escenario intermedio, las áreas específicas ocupan relativamente menos espacio en la vida social de los mismos individuos que las frecuentan. En este escenario, los orígenes diferenciados de la población no implican prácticamente dificultades de acceso insalvables a ningún sector importante del área central. Gran parte de la vida social de las poblaciones de origen extranjero se desarrolla en esta área central de la sociedad, a la vez que otra parte de su vida social encuentra su marco preferente en las áreas específicas. El conjunto de la población ha incorporado bastantes elementos culturales de las poblaciones de orígenes específicos y las relaciones interpersonales entre la poblaciones de diversos orígenes se producen con fluidez.

Además de las múltiples combinaciones posibles hay que advertir que los individuos, familias o grupos dentro de poblaciones de los mismos orígenes nacionales pueden seguir evoluciones muy diferenciadas entre sí en su ubicación en el país de destino. Así mismo, los diversos orígenes nacionales pueden dar lugar a dinámicas específicamente diferenciadas.

12. La integración social y la población de raigambre autóctona. El mantenimiento y el aumento de la cohesión social a lo largo del tiempo, no sólo comporta cambios considerables en las poblaciones quellegan de fuera, sino que también pide una disposición abierta a algunos cambios en la población de raigambre autóctona. La pura asimilación tiene pocas probabilidades de éxito e implica la pérdida de enriquecimientos culturales considerables. Una sociedad integrada intercultural ha de combinar la cohesión social con la existencia de grupos sociales con identidad parcialmente diferenciada. La pérdida de la identidad es uno de los miedos con mayor capacidad de revolver los ánimos en actitudes encontradas. Y esto vale para los miedos de la población de raigambre autóctona a perder su identidad, así como para los miedos, ansiedades eincertidumbres de las poblaciones en procesos migratorios ${ }^{16}$. Lo saben bien los agitadores de uno u otro signo. Por

16 La permanencia y las evoluciones de la identidad durante los procesos migratorios en sus 
el contrario, una serena conciencia de identidad puede ser el mejor antídoto ante los miedos de perderla; y también una apertura a la incorporación de nuevos elementos, que hace de la propia identidad algo vivo, sujeto a evolución. Aplicándolo a las nacionalidades europeas, la pervivencia de una identidad (francesa, danesa, escocesa, portuguesa, flamenca, alemana...) no puede presuponer una adecuación total entre las manifestaciones de estas identidades hace cien, cincuenta, veinticinco años y la forma en que son vividas en el presente o lo serán en el futuro, sin que ello presuponga su desaparición. Por el contrario, la rigidez en mantener sin cambios estas identidades, además de dificultar su pervivencia, puede ser un síntoma de debilidad de las mismas identidades nacionales. No son sólo los aportes de la población de origen foráneo los que pueden traer cambios, la globalización económica y la hegemonía cultural vehiculada por los medios de comunicación y la producción y distribución de sus productos está afectando a niveles más profundos, posiblemente, que los cambios relacionados con el incremento de población de raigambres extranjeras. La capacidad potencial de una identidad nacional para enriquecerse con las aportaciones culturales provenientes de la población de origen extranjero ofrece una medida de calidad y robustez de la misma identidad nacional.

\section{Globalización, desarrollo y retornos}

13. La globalización y sus efectos desiguales en el Norte y en el Sur. La globalización está actualmente afectando desigualmente a las diversas poblaciones del mundo. La grandes desigualdades existentes entre los niveles de desarrollo humano, las diferencias de "bien-estar" agudamente percibidas y amplificadas por la difusión que ha traído la globalización de las imágenes (televisión, cinema...) y las mayores facilidades de transportes y comunicaciones, entre otros factores, mueven y moverán, probablemente

diversas fases y generaciones: la de los primi migrantes, la de sus hijos y la de sus nietos, es un tema amplísimo e importante que cuenta con abundante bibliografía y que aquí no pretendemos desarrollar. Indicamos nada más como contrapunto a las evoluciones identitarias a las que se ven sujetos los grupos y los individuos, el que estos cambios no hagan peligrar la estructura de la personalidad de los individuos, dado que el derecho a la salud, reconocido entre los derechos fundamentales del hombre, incluye el derecho a la salud mental. Es preciso tener en cuenta en este tema las aportaciones de la psicología y de la psiquiatría, incorporadas al conjunto de aportaciones interdisciplinares, imprescindibles para iluminar y completar los conocimientos sobre el tema. 
durante algunos años, considerables flujos de población de los países del Sur ${ }^{17}$ a los de Norte de mundo. Mientras dure esta fase demográfica en que se dan diferencias considerables en la proporción que representa lajuventud respecto a la población total entre países del Sur y países del Norte ${ }^{18}$, se reforzarán las tendencias migratorias descritas. Muchos confluyen en afirmar que el auténtico desarrollo humano de los países del Sur será el único capaz de frenar efectivamente las grandes corrientes migratorias hacia los países del Norte. Así se expresaba el documento conclusivo de la Conferencia Internacional de Población y Desarrollo del Cairo: “Para que la migración internacional tenga dimensiones manejables a largo plazo es preciso que la opción de permanecer en el propio país sea viable para todos"(Naciones Unidas 1994, n.10.1). Esta lógica es congruente con lo que ya había expresado J oanot Martorell en Tirant lo Blanc: "Qui be està no es cuita moure"19. Las exigencias de este desarrollo humano, sotenible y solidario ${ }^{20}$ tienen, con todo, razones mucho más profundas para ser promovidas en un mundo en el que urge un nuevo orden mundial acorde con estas exigencias.

14. Se utiliza a veces dialécticamente el desarrollo de los países de origen como alternativa a las migraciones. Pero no se puede olvidar en este tema la secuencia temporal: el desarrollo ya conseguido refrena efectivamente las emigraciones, impulsa al retorno de parte de la población que emigró y acaba atrayendo inmigrantes de otros orígenes. Es un proceso que los países del sur de la Unión Europea -Italia, España, Grecia, Portugal- han conocido con algunas diferencias de calendario, en los últimos treinta o cuarenta años. Pero no hay que confundir los planos temporales: las prime-

17 Sur y Norte se emplean aquí más que en su sentido estrictamente geográfico, en un sentido geo-político, como equivalentes prácticamente, a lo que en lenguaje de las Naciones Unidas se indica como países en desarrollo y países desarrollados, o en otras terminologías, Tercer Mundo y Primer Mundo.

18 En este punto conviene ir actualizando las prospectivas: las más recientes tienden a acortar diferencias con mayor rapidez de lo que habían previsto prospectivas anteriores. Así mismo, las diferencias por países concretos son muy grandes. Y la clasificación en sólo dos bloques: Sur y Norte resulta en este tema excesivamente estrecha.

19 “Quien bien está no se preocupa de moverse". Citado por A. Pascual y J. Cardelús (1998), p. 189.

20 Un ejemplo de gran impacto en estas exigencias solidarias es la necesidad de cambiar las condiciones del comercio internacional en las cuales los países más ricos han ido imponiendo la salida sin cargas de sus exportaciones a los países más pobres y en cambio han dificultado las exportaciones de los productos claves de estos países. La OMC tiene en este punto un largo trecho por delante. 
ras fases de desarrollo incrementan incluso las emigraciones ${ }^{21}$. Y éstas, a su vez, pueden resultar factores de desarrollo del país de procedencia, según como se encaucen las remesas de los emigrantes, y según cómo vayan variando los desequilibrios de "bien-estar" percibido entre el país de inmigración y el de origen.

15. La posibilidad de retorno con mucha frecuencia está presente inicialmente en el horizonte de quien emigra. Con el paso del tiempo sucede con frecuencia que el proyecto inicial se retrasa, se modifica, o se mantiene. En la realización efectiva del retorno o no retorno, los hijos suelen resultar un factor crucial. Si se va produciendo un efectivo desarrollo en los países de origen, es fácil pensar que surgirán allí condiciones tales que puedan ofrecer puestos de trabajo particularmente adecuados para quienes emigraron del país, o para sus descendientes, y que adquirieron experiencia o cualificación en algunas empresas del Norte. Las realizaciones prácticas de esta intuición, válida en sí misma, no acaban de resultar eficaces si no se ajustan bien las condiciones a las expectativas de quienes se presumen interesados en el retorno.

\begin{abstract}
16. Necesidad y oportunidad de abrir los horizontes del conocimiento y de los intereses de la población europea a las realidades y las exigencias del mundo real, a partir de iniciativas concretas y eficaces. La incorporación a los países de Europa de poblaciones originadas de inmigraciones procedentes de países del Sur ofrece unas o portunidades singulares de enriquecimiento humano y cultural, también para las sociedades europeas. Están todavía abiertas, en gran parte, las posibilidades de potenciar o de dejar perder estas oportunidades. El Norte ha desarrollado unos niveles tecnológicos y económicos considerables, desde donde fácilmente pasa la gran mayoría de su población al desconocimiento, "des-precio" y "des-interés" por los valores, países y culturas del Sur. Si se avanza por el camino de una homogeneización cultural progresiva por imposición y exclusión, la humanidad puede perder enormes filones de riqueza humana.
\end{abstract}

${ }^{21}$ Recuérdese, por ejemplo, que en España los años sesenta fueron los de los primeros planes de desarrollo y a la vez fueron años de grandes migraciones interiores y emigraciones a la Europa transpirenaica. 


\section{Bibliografía}

BOUCHer, Manuel (2000), Les théories de l'intégration, París, L'Harmattan, $337 \mathrm{pp}$.

Comisión Europea (2000), Comunicación de la Comisión al Consejo y al Parlamento Europeo sobre una política comunitaria de inmigración, Bruselas, 22 de noviembre.

ENTZINGER, Han B. (1990), "L'emergenza delle politiche di integrazione per gli immigrati in Europa", en BASTENIER, A.; DASSETto, F. y otros (1990), Italia, Europa e nuove immigrazioni, Torino, Edizioni della Fondaziones Giovanni Agnelli, pp. 179-200.

Eurostat (2000), European social statistics. Migration. Luxembourg, 2000 Edition, European Comunities, $233 \mathrm{pp}$.

EUROSTAT (2000), Push and pull factors of international migration. A comparative report. Luxembourg, 2000 Edition, European Communities, 161 pp.

GrudzIELSKI, S. (1990), "Les politiques d'intégration des États européens", Séminaire sur “Les immigrés et les réfugiés à l'aube de 1993", Gap. Aout 1990.

International Organization for Migration (IOM) (2000), World Migration Report 2000. A copublication by IOM and the United Nations, under the direction of Peter Schatzer, $287 \mathrm{pp}$.

OeCD / Sopemi 2000 (2001), Trends in International Migration. Annual Report. 2000 Edition, 376 pp.

Pascual, A. y Cardelús, J . (1998), “Migracions a Catalunya: entre la mobilitat i I'assentament", en GINER, S. (dir.) La societatcatalana, Institut d'Estadística de Catalunya, pp.189-200.

Perotti, Antonio (1993), “La pluriculturalité des societés européennes: I'etat des lieux", en Migrations Societé, vol. 5, no 30, nov.-déc., pp. 53-70.

PISELLI, F. (1997), "Il network sociale nell'analisi dei movimienti migratori", Studi Emigrazione, vol. XXXIV, num. 125, Roma, Centro Studi Emigrazione, pp. 2-16.

Recolons, Lluís (2001), "Migration in the World: Links with Human Richness and Material Poverty", en D'SouzA, Stan (editor) Population and Poverty Issues at the Dawn of the $21^{\text {st }}$ Century, New Delhi, Indian Social Institute, pp. 35-63. 
United Nations/Naciones Unidas (1995) Población y desarrollo. Programa de Acción adoptado en la Conferencia Internacional sobre la Población y el Desarrollo. El Cairo, 5 a 13 de septiembre de 1994. Vol. 1, n. 10.1.

United Nations (2000) Replacement Migrations: Is it a Solution to Declining and Ageing Populations?, Population Division.

Werbner, P. (1990) The Migration Process, Munich, Berg, New York-Oxford. 